\title{
Fabrication of Dendritic Gold Nanoparticles Using an Ionic Polymer Template
}

Jichun Zhang, ${ }^{1}$ Lingjie Meng, ${ }^{1}$ Dongbin Zhao, ${ }^{2}$ Zhaofu Fei, ${ }^{2}$ Qinghua Lu, ${ }^{1 *}$ Paul J. Dyson ${ }^{2 *}$

1. School of Chemistry and Chemical Technology, Shanghai Jiao Tong University, Shanghai, 200240, P. R. China.

2. Institut des Sciences et Ingénierie Chimiques, Ecole Polytechnique Fédérale de Lausanne (EPFL), CH-1015 Lausanne, Switzerland.

E-mail:qhlu@sjtu.edu.cn; paul.dyson@epfl.ch

\section{Supporting information}

Figure S1: UV-Vis spectra of sample A, PMVIC:HAuCl $\mathrm{P}_{4}=0: 1, \mathrm{NaBH}_{4}: \mathrm{HAuCl}_{4}=2: 1$, $25^{\circ} \mathrm{C}$ in water.

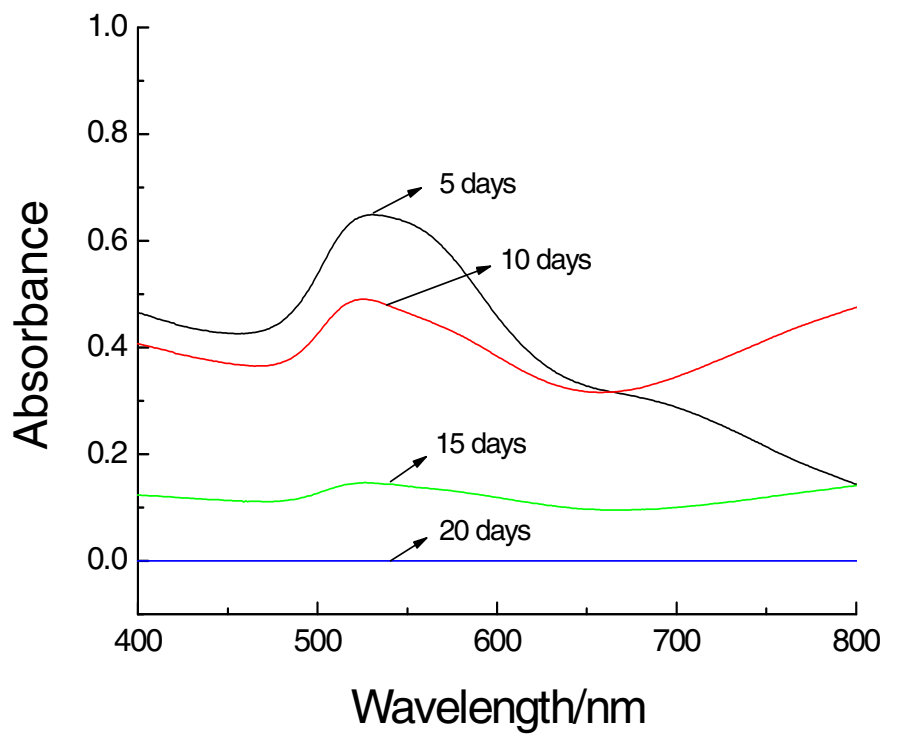


Figure S2: TEM image of gold NPs (Conditions: PMVIC:HAuCl $4=2: 1, \mathrm{NaBH}_{4}: \mathrm{HAuCl}_{4}=$ $2: 1,25^{\circ} \mathrm{C}$ in water. All ratios are molar ratios.)

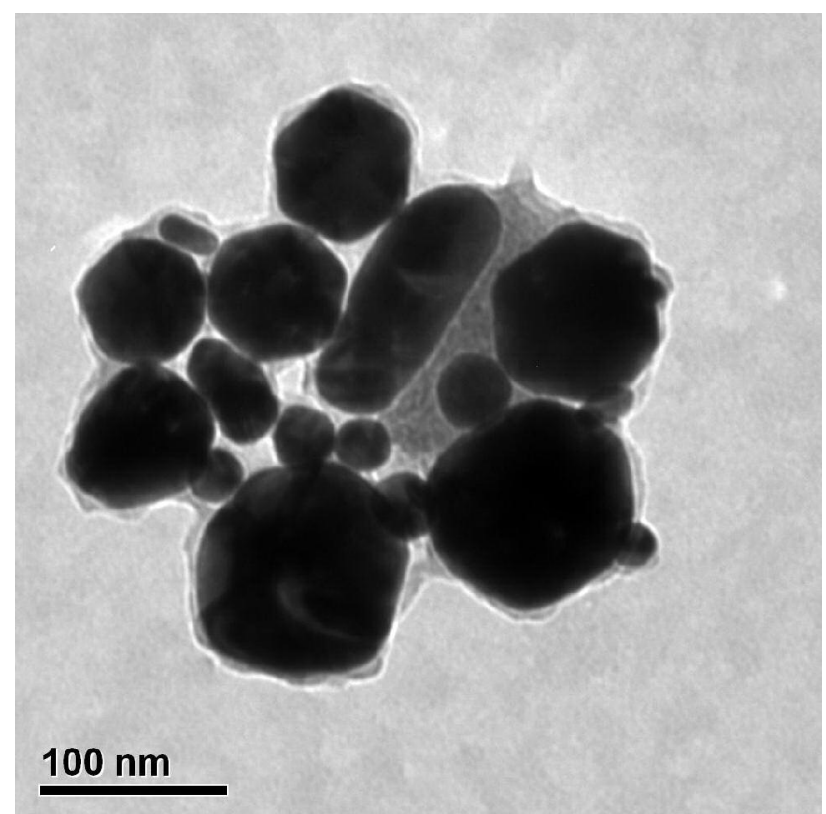

Figure S3: TEM image of gold NPs (Conditions: PMVIC:HAuCl $\mathrm{H}_{4}=5: 1, \mathrm{NaBH}_{4}: \mathrm{HAuCl}_{4}=$ $2: 1,25^{\circ} \mathrm{C}$ in water. All ratios are molar ratios.)

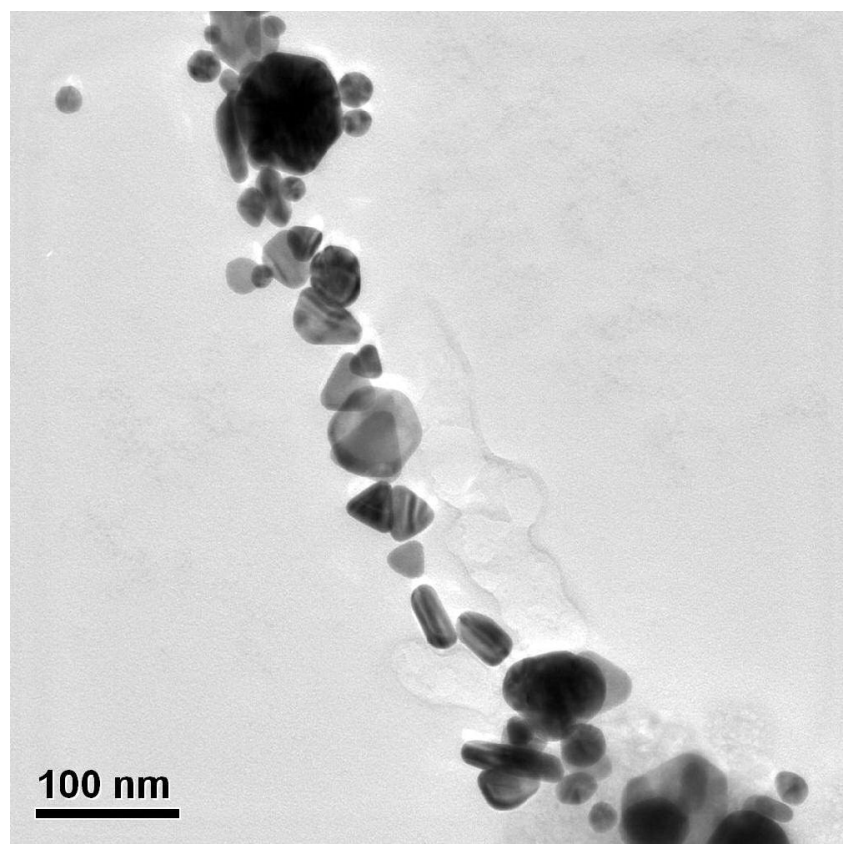


Figure S4: TEM image of gold NPs (Conditions: PMVIC:HAuCl $4=30: 1, \mathrm{NaBH}_{4}: \mathrm{HAuCl}_{4}=$ $2: 1,25^{\circ} \mathrm{C}$ in water. All ratios are molar ratios.)

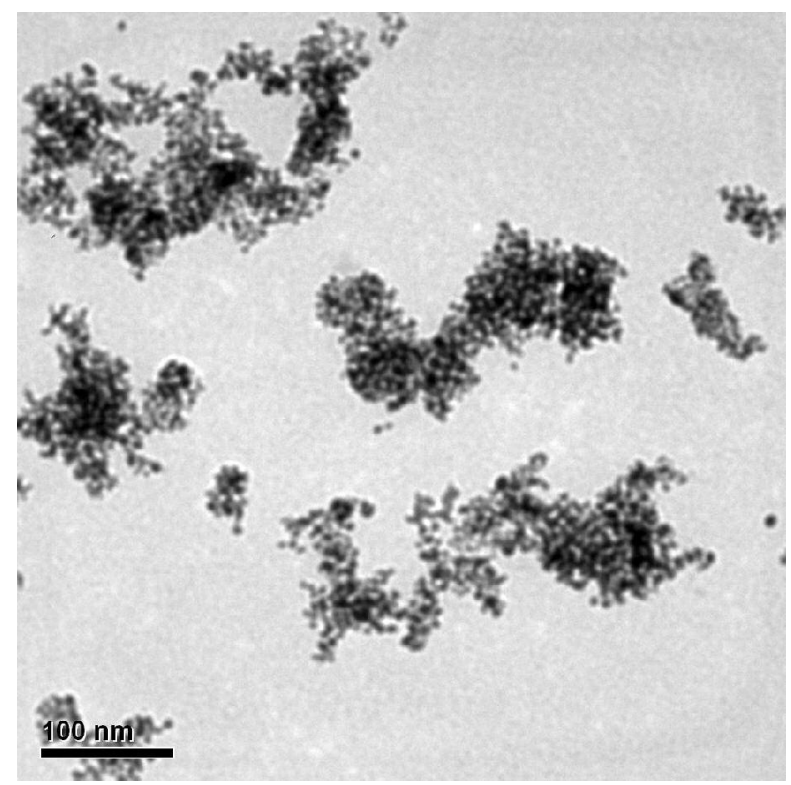

Figure S5 Energy-dispersive X-ray spectroscopy (EDS) of sample obtained from experiment E.

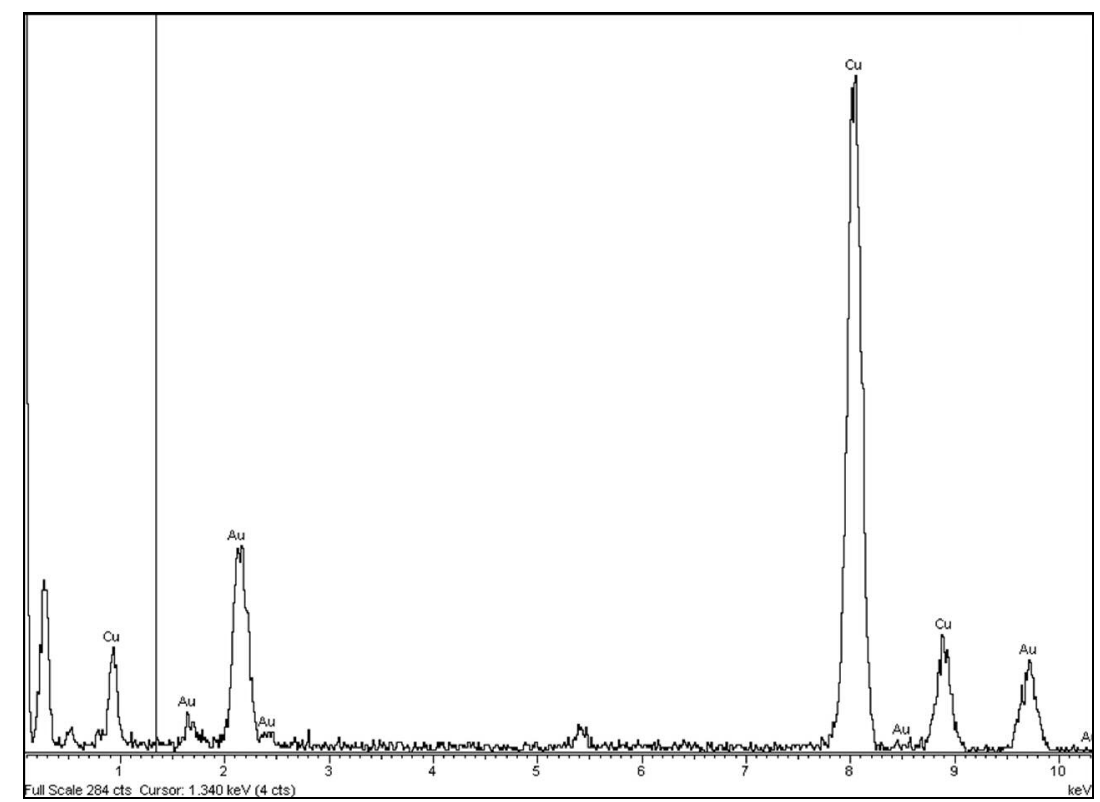


Figure S6 Energy-dispersive X-ray spectroscopy (EDS) of sample obtained from experiment F.

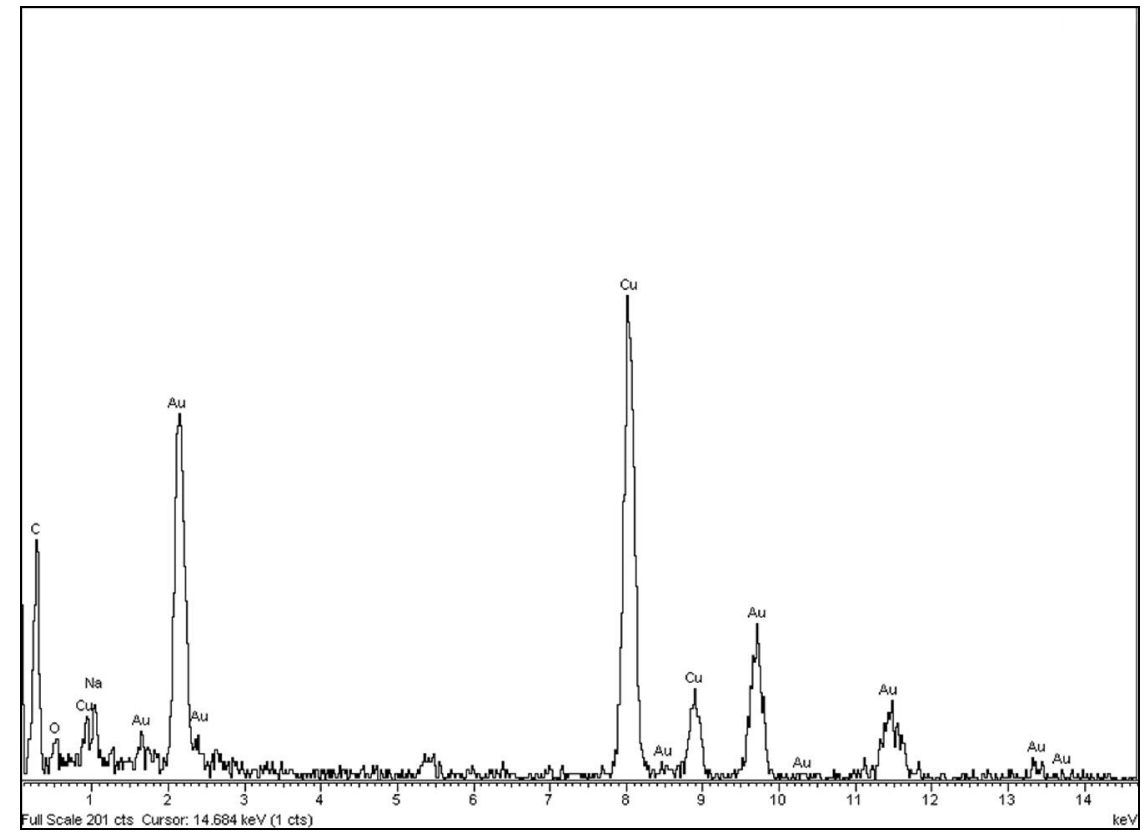

Figure S7 Energy-dispersive X-ray spectroscopy (EDS) of sample obtained from experiment G.

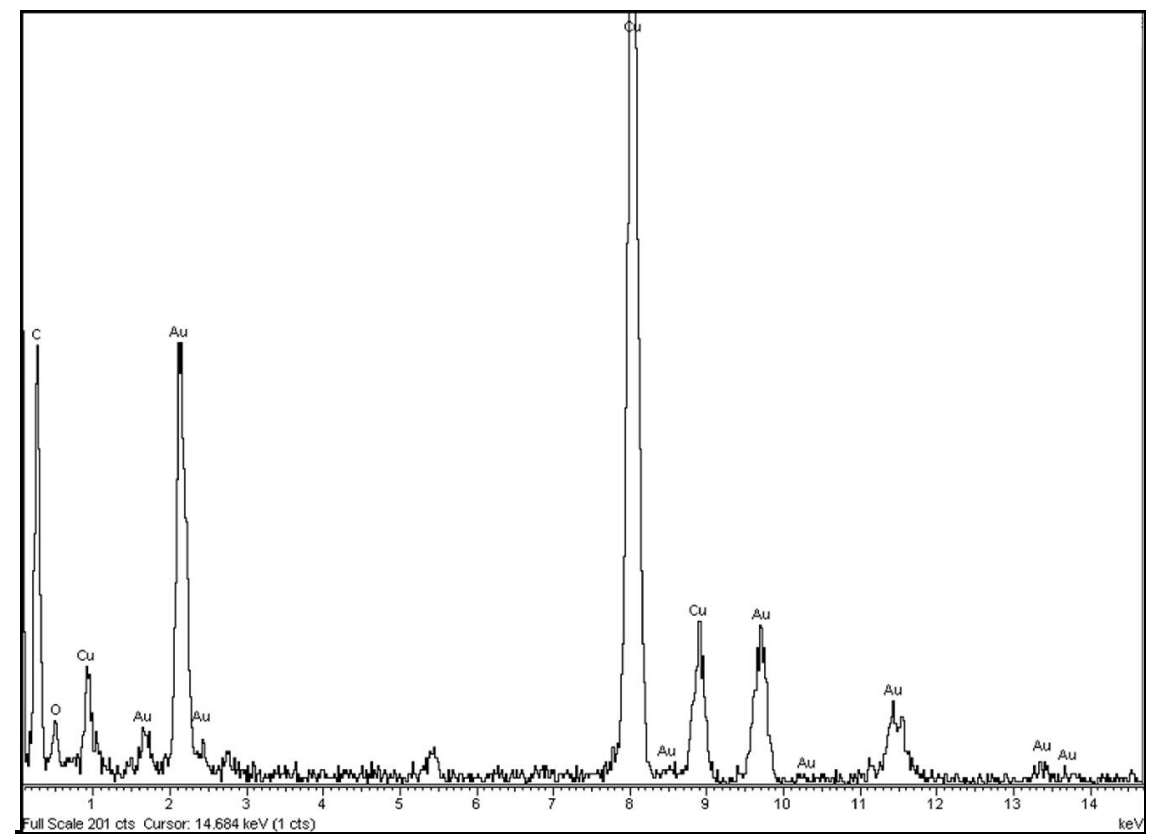


Figure S8 Energy-dispersive X-ray spectroscopy (EDS) of sample obtained from experiment H.

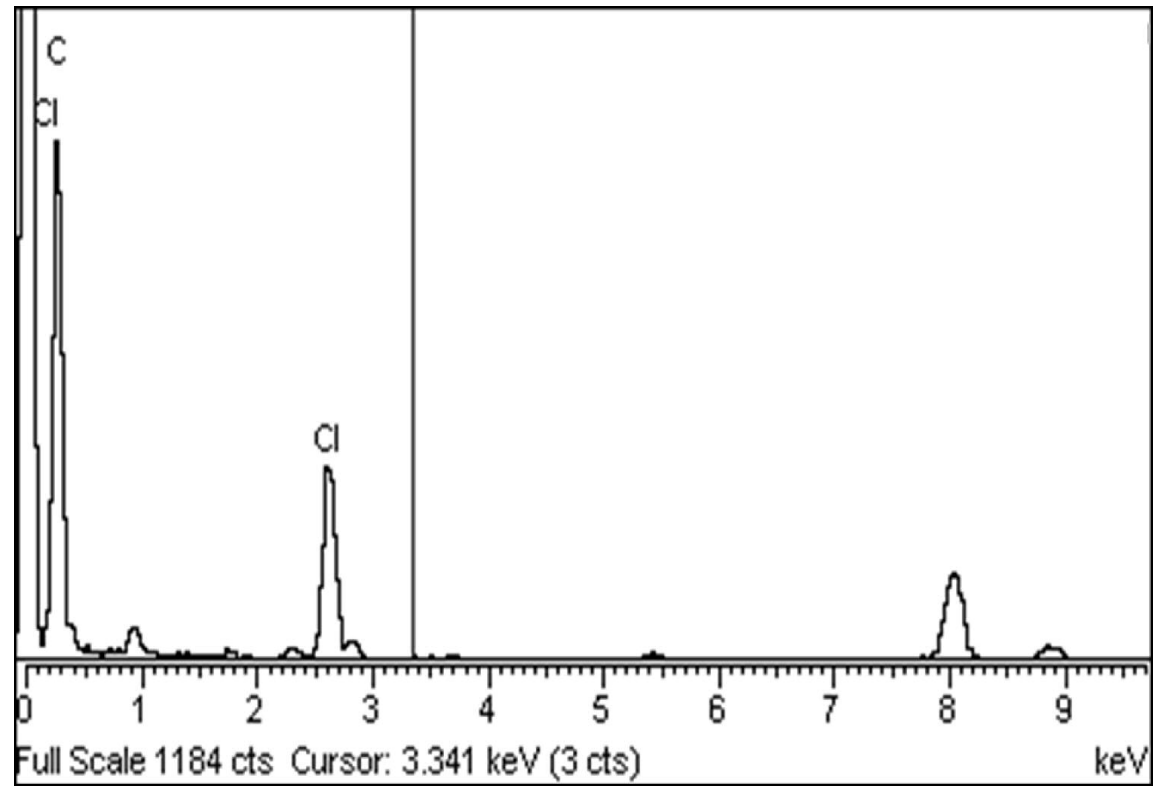

Figure S9 Energy-dispersive X-ray spectroscopy (EDS) of PMVIC.

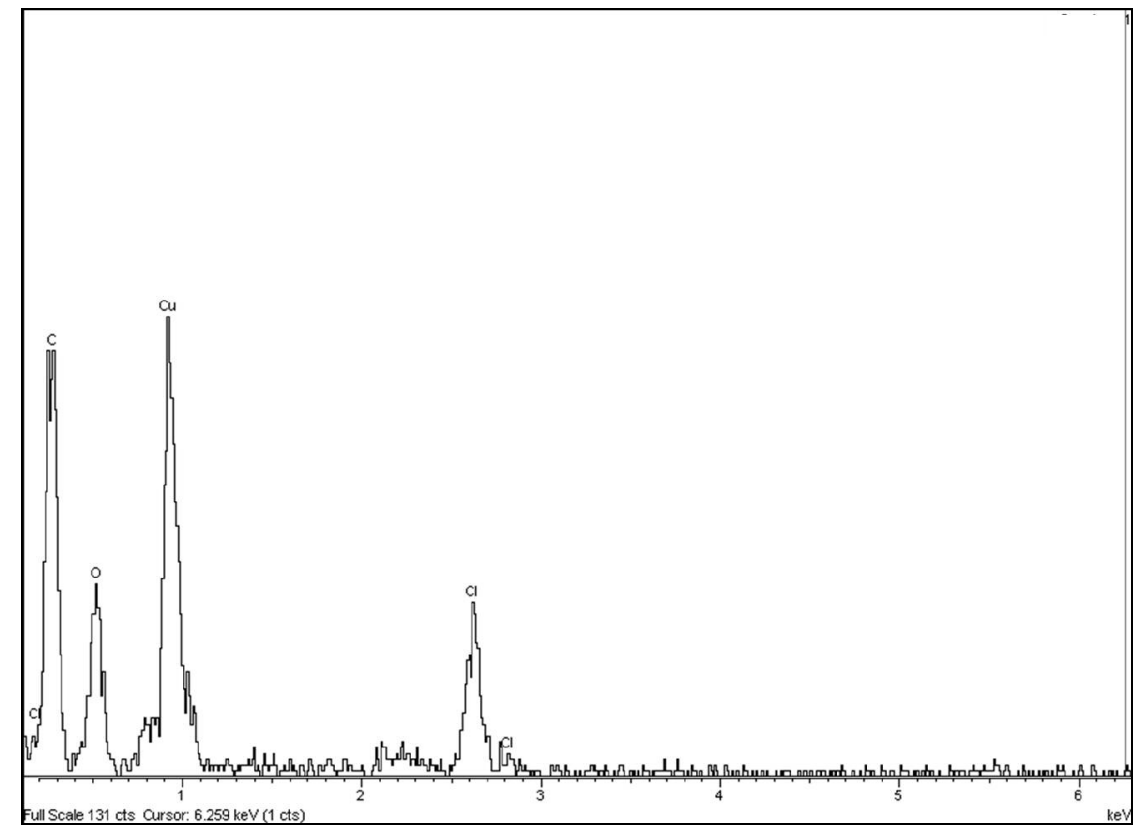


Figure S10 FE-SEM image of PMVIC obtained from acetone-water (5/95, v/v) after drying at $45^{\circ} \mathrm{C}$ for $24 \mathrm{~h}$.

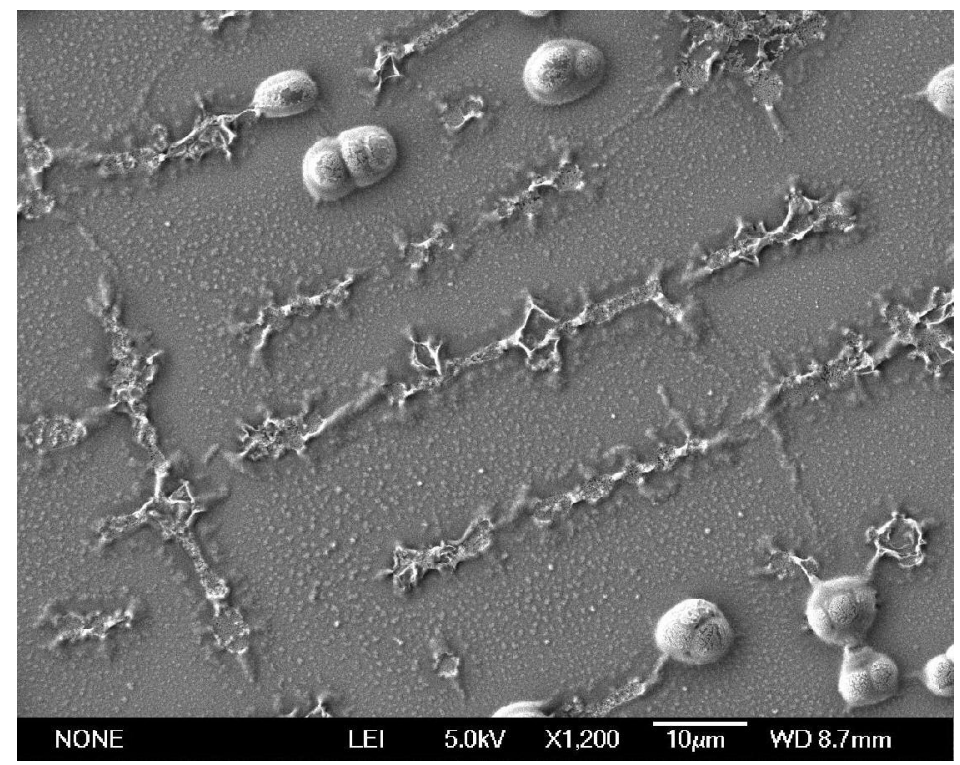

Figure S11 ${ }^{1} \mathrm{H}$ NMR in $\mathrm{D}_{2} \mathrm{O}$ of PMVIC from ethanol-water $(24: 76$, v/v) after evaporation at $25^{\circ} \mathrm{C}$.

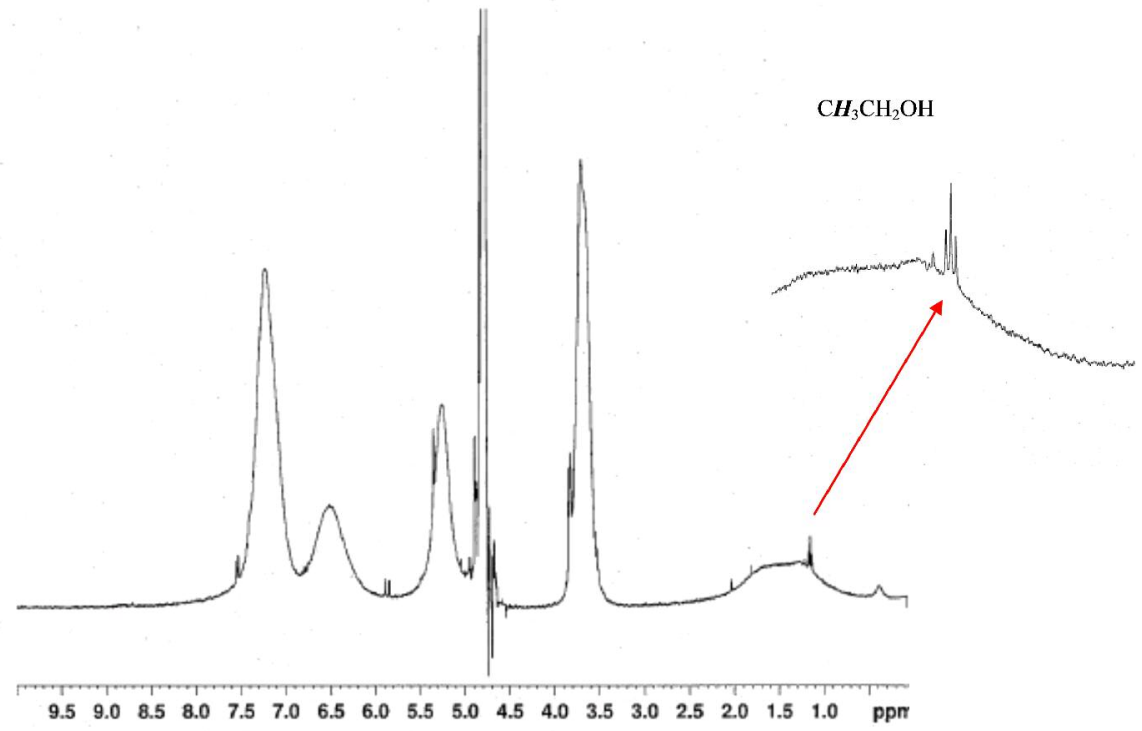

